\section{Fanconi anemia - learning from children}

\author{
Johanna Svahn, Carlo Dufour \\ Department of Pediatric Hematology \\ Oncology and Bone Marrow \\ Transplantation, Gaslini Childrens \\ Hospital, Genova, Italy
}

\section{Abstract}

Fanconi Anemia (FA) is a rare autosomic recessive and $\mathrm{X}$-linked disease with chromosomal instability after exposure to crosslinking agents as the hallmark. Clinical features of FA are somatic malformations, progressive bone marrow failure and cancer proneness, however there is wide clinical heterogeneity. The symptom most frequently and early associated with morbidity and mortality is progressive pancytopenia in the first decade of life although acute myelogenous leukemia (AML) or myelodysplastic syndrome (MDS) can appear before aplastic anemia. Squamous cell carcinoma (SCC) of the head-neck, intestinal or genital tract has a very high incidence in FA and can appear at young age. This paper will focus on treatment of bone marrow failure in FA.

\section{Introduction}

Fanconi Anemia (FA) is a rare autosomic recessive and $\mathrm{X}$-linked disease with wide clinical and biological heterogeneity. The gold standard diagnostic criteria of FA is increased chromosome fragility after exposure to alchylating agents such as diepoxybutane (DEB) or mitomycine $\mathrm{C}$ (MMC). The most frequent clinical features are progressive bone marrow failure, somatic abnormalities and cancer susceptibility. Altered skin pigmentation and/or café au lait spots, short stature, thumb or thumb and radial anomalies, abnormal male gonads, microcephaly, eye anomalies, structural renal defects, low birth weight, developmental delay, and abnormal ears or hearing are the most frequent birth defects. However about $25-40 \%$ of FA patients have a normal or nearly normal somatic phenotype. ${ }^{1}$ The reported incidence of FA, probably underestimated, is 3 cases/million newborn/year and the disease is slightly more frequent in males than females, the ratio being $1.3 / 1$. The carrier frequency is 1/300 in USA and western Europe, whereas among some populations such as South African Afrikaaners, Ashkenazi Jews and Spanish Gypsies the frequency is higher, about $1 / 90-1 / 100$, due to genetic founder effects..$^{1-3}$

To date there are $14 \mathrm{FA}$ complementation groups corresponding to 14 different cloned genes: FANCA, B, C, D1, D2, E, F, G, I, J, L, M, N and $P$. More than $2 / 3$ of Fanconi patients belong to FA-A, FA-C or FA-G group with FA-A accounting for more than $50 \%$. Although most are unique genes, several were previously known, including FANCD1 (BRCA2), FANCG (XRCC9), FANCI (KIAA1794), FANCJ (BRPI1/BACH1), FANCL (PHF9/POG), FANCM (Hef), FANCN (PALB2) and FANCP (SLX4). Heterozygotes for BRCA2 and possibly BACH1 and PALB2 are at increased risk of breast cancer and other cancers. In addition there are 3 other genes involved in the pathway but not yet found in any patient and therefore not formally designated as FA genes: RAD51C, DDX11, FAAP20. The Fanconi anemia proteins A, B, C, E, F, G, L and $\mathrm{M}$ appear to form a nuclear complex, which leads to ubiquitination of the I and D2 proteins; the latter is involved in DNA damage response mechanisms in cooperation with FANCD1, FANCJ, FANCN and FANCP, as well as BRCA1, RAD51, Mre11, and other proteins.

The widely variant FA phenotype may depend on whether the mutation in the involved FA gene is null or leads to a partially functional gene product rather than the specific gene that is involved. Attempts to do genotype-phenotype correlations in FA have shown contrasting results between different studies and high-light the genetic and clinical heterogeneity in the population. In addition, somatic reversion of the germ-line mutation in a FA gene leading to mosaicism, defined by the presence of two genetically different cell populations in the organism, one normal and one Fanconi, furthermore increases the difficulty in genotype- phenotype correlations. Hence, the specific role of the Fanconi Anemia proteins in the pathogenesis of somatic abnormalities, bone marrow failure, or oncogenesis remain to be clarified.

Other than birth defects the most frequent presentation of FA leading to diagnosis is progressive bone marrow failure appearing during the first decade of life. Early signs before peripheral blood cytopenia becomes evident may be progressively increasing mean corpuscular volume (MCV) and HbF. Actual aplastic anemia may be preceded by myelosdysplastic syndrome (MDS) or acute myelogenous leukemia (AML) and chromosomal aberrations involving chromosome 3 and 7 lead to increased risk of developing MDS/AML. ${ }^{4}$ As cancer can be the only manifestation of FA, it should be suspected in cases of early onset head-neck squamous cell carcinoma (SCC), esophageal or vulvar cancer. This paper will focus on management and treatment of bone marrow failure in FA.

Marrow failure in FA prompts a comprehensive monitoring plan consisting of clinical examination and at least yearly bone marrow studies, including morphology, cytogenetics, FISH, colony studies and immunophenotyping.
Correspondence: Carlo Dufour, Haematology Unit, Department of Pediatric Haemato-Oncology, G. Gaslini Children's Hospital, Genova, Italy. E-mail: carlodufour@ospedale-gaslini.ge.it

Key words: Fanconi anemia.

Received for publication: 4 May 2011.

Accepted for publication: 4 June 2011.

This work is licensed under a Creative Commons Attribution NonCommercial 3.0 License (CC BYNC 3.0).

(C) Copyright J. Svahn and C. Dufour, 2011

Licensee PAGEPress, Italy

Pediatric Reports 2011; 3(s2):e8

doi:10.4081/pr.2011.s2.e8

At diagnosis parents and siblings should be evaluated by DEB test and by molecular genetic testing if the patient has a known mutation. At diagnosis, even if the marrow failure is at a very early stage, the patient and family should be HLA typed, because 1 st choice treatment is hematopoietic stem cell transplantation (HSCT) if an HLA matched family donor is available. If no family donor is available an unrelated donor search should be initiated as soon as possible. The reason for the urgency to identify a donor is because the earlier transplant is done, to a younger patient who has not received transfusions, the better is the outcome.

Due to the chromosome fragility inherent to the FA cells, FA patients display extraordinary toxicity when treated with chemo- or radiotherapy. Therefore the conditioning regimen prior to HSCT must be reduced compared to other patient groups. Using irradiation in the preparative regimen has been debated over the past decades. Several groups have reported results after transplant with or without total body irradiation (TBI), the results are summarized in Table 1. A registry analysis that compared irradiation vs non irradiation in $148 \mathrm{FA}$ patients registered to the Center for International Blood and Marrow Transplant Research (CIBMTR) database receiving an HLA-matched sibling transplant between 1991 and 2001 showed no differences in engraftment, acute and chronic GVHD, transplant related mortality (TRM) or OS in the two groups. ${ }^{5}$ The message was therefore in support to the use of non-irradiation preparative regimen. The follow-up was too short to evaluate if irradiation was associated with increased risk of tumours.

Regarding timing of HSCT from a matched family donor, published experience leads us to suggest that transplant should be performed in early marrow failure, as manifested by mild cytopenia and hypoplasia of marrow hematopoietic tissue but before cytopenia becomes se- 
Table 1. Matched family donor transplant: conditioning regimen and outcome.

\begin{tabular}{|c|c|c|c|c|c|}
\hline & $\begin{array}{l}\text { Dufour et al. } \\
(\text { BJH 2001)18 }\end{array}$ & $\begin{array}{l}\text { Farzin et al. } \\
(\text { BJH 2007)19 }\end{array}$ & $\begin{array}{c}\text { Tan et al. } \\
(\mathrm{PBC} 2006)^{20}\end{array}$ & $\begin{array}{l}\text { Ayas et al. } \\
(\text { BMT 2008) }\end{array}$ & $\begin{array}{l}\text { Bonfim et al. } \\
(\text { BBMT 2007)9 }\end{array}$ \\
\hline Patient nr & 27 & 35 & 11 & 34 & 67 \\
\hline Conditioning & $\begin{array}{l}\text { TAI/TBI 500cGy, } \\
\text { LDCY or HDCY }\end{array}$ & $\begin{array}{l}\text { TAI/TBI 400cGy, } \\
\text { LDCY, ATG }\end{array}$ & $\begin{array}{c}\text { LD CY + FLU } \\
125 \mathrm{mg} / \mathrm{m}^{2} \text {, ATG, TCD }\end{array}$ & $\begin{array}{l}\text { CY } 60 \mathrm{mg} / \mathrm{kg}, \\
\text { ATG }\end{array}$ & CY 60 mg/kg \\
\hline Graft failure & $8 \%$ & $5,7 \%$ & $9 \%$ & 0 & $10,5 \%$ \\
\hline Ac GVHD & $36 \%$ & $14,2 \%$ & 0 & & $17 \%$ \\
\hline Cr GVHD & $12,5 \%$ & $12 \%$ & 0 & & $28 \%$ \\
\hline TRM & $18,5 \%$ & $8,5 \%$ & $9 \%$ & & $9 \%$ \\
\hline Late tumours & 0 & $5,7 \%$ & & & $3 \%$ \\
\hline Follow-up & $3 \mathrm{yrs}$ & $10 \mathrm{yrs}$ & $2 \mathrm{yrs}$ & $2,9 \mathrm{yrs}$ & $3,7 \mathrm{yrs}$ \\
\hline OS & $81,5 \%$ & $83 \%$ & $100 \%$ & $97 \%$ & $97 \%$ \\
\hline EFS & & & $82 \%$ & $82 \%$ & \\
\hline
\end{tabular}

LDCY: low dose cyclophosphamide, 20 mg/kg; HD CY: high dose cyclophosphamide, 100-200 mg/kg; TCD: T Cell depleted graft; ATG: anti lymphocyte globuline. vere, i.e. before platelets decrease below $40 \times 109 / \mathrm{L}$, before transfusion requirement, and before appearance of cytogenetic aberrations involving chromosome 3 and 7 and/or AML. Age at transplant is consistently a prognostic factor with better outcome if performed before 10 years. The evidence suggest that conditioning regimen for a matched family donor transplant should be without irradiation, using fludarabine and cyclophosphamide and with T cell depletion (TCD), either of the graft or in vivo with Mabcampath for example, to prevent GVHD.

In case a matched family donor is not available, a donor search in international registries should be started as soon as possible and transplant should be performed essentially with the same criteria as a matched family donor transplant, i.e. before severe cytopenia requiring transfusions and before appearance of a cytogenetic clone and/or AML. Regarding the conditioning regimen in alternative donor transplants, there is no doubt that fludarabine has changed the outcome relevantly, from previously very poor, improving survival and engraftment and reducing early mortality and transplant related mortality (TRM). ${ }^{6}$ The use of irradiation varies between countries and transplant centres, as summarized in Table 2. In three consecutive phase II clinical trials assessing the optimal approach to alternative donor transplants, MacMillan et al. confirmed in multivariate analysis that age $>10$ years and any transfusion prior to transplant was associated with higher 3 -year mortality. Among these trials, a TBI dose de-escalation from 300 to 150 cGy led to secondary graft failure in $2 / 2$ pts and therefore dose de-escalation was stopped and returned to $300 \mathrm{cGy}^{7}$ A single-center report of 7 patients transplanted with alternative donors without irradiation resulted in $22 \%$ rejection rate which however could be recuperated with a second transplant and all patients were alive at median 3 years follow-up. ${ }^{8}$ Bonfim et al. re- ported 60 patients receiving alternative donor transplants without irradiation obtaining OS at 5 years $92 \%$ for patients below 10 years of age and $53 \%$ for patients above 10 years. Noteworthy in this report, 10 patients developed tongue carcinoma, 7 of whom had had GVHD. ${ }^{9}$ (C. Bonfim, update of ref 9 as oral communication, FARF Scientific Symposium 2010) This highlights the importance of reducing GVHD, by TCD of the graft or in vivo TCD using Mabcampath and/or ATG.

Unrelated Cord blood (UCB) as an alternative stem cell source to bone marrow or peripheral blood has been reported in a registry based analysis of 93 UCB in FA where OS was $53 \%$ with Fludarabin in the conditioning regimen (vs 19\% non Fludarabin). There were relatively high figures of GVHD and TRM, 32\% and $59 \%$ respectively. 10 As of today, UCB transplant should be considered only when other alternative donor stem cell source cannot be found. Preliminary results from a retrospective analysis of the EBMT database show that mismatched or haploidentical family donors may be a valid option if no matched unrelated donor can be found (E. Korthof, oral communication FARF Scientific Symposium 2010). In summary, alternative donor transplants are improving in survival, getting close to that of matched sibling donor transplants, whereas TRM and GVHD are still a problem. It is still an unresolved issue whether to perform irradiation or not. Furthermore, the intrinsic cancer proneness in FA significantly increases with acute severe and chronic GVHD and in general a 4.4-fold higher risk for SCC was found in patients who received transplants vs who did not. The cumulative incidence of SCC was $24 \%$ at 15 years after transplant and SCC manifested at younger age in transplanted FA patients compared to non transplanted.11

Other treatment alternatives for marrow failure in FA are only temporary options awaiting HSCT which is the only treatment that can cure bone marrow failure and prevent the risk of hematologic malignancy. The use of androgens, oxymetholone at the dose of 2-5 $\mathrm{mg} / \mathrm{kg} /$ day, can bridge the gap to HSCT, but should be avoided long-term due to side-effects including masculinization, final short stature, peliosis hepatis, liver adenomas and hepatocellular carcinomas. Androgens were reported to adversely affect the outcome of subsequent HSCT in some studies 12 but not in others. ${ }^{13}$ Hematopoietic growth factors such as EPO and G-CSF have no demonstrated effect. G-CSF has the potential risk of stimulating clonal escape and should be used only in rare cases of severe infections in neutropenia. Anti-fungal agent voriconazole should be used with caution due to increased risk of SCC14 (AIFA nota informativa 22/9/10). Experimental trials studying the safety and efficacy ofanti-TNF alpha agent etanercept in FA, based on the in vitro beneficial effect of etanercept on colony formation in FA marrow mononuclear cells ${ }^{15}$ are currently being evaluated.

There is limited experience on treatment of
Table 2. Matched unrelated donor transplants: conditioning regimen and outcome.

\begin{tabular}{|c|c|c|c|c|c|}
\hline & $\begin{array}{c}\text { MacMillan } \\
\text { et al. } \\
\text { (BBMT 2009)9 }^{9}\end{array}$ & $\begin{array}{l}\text { Chaudhury } \\
\text { et al. } \\
\text { (BJH 2008)22 }\end{array}$ & $\begin{array}{c}\text { Yabe } \\
\text { et al. } \\
(\text { BJH 2006)23 }\end{array}$ & $\begin{array}{c}\text { Bonfim } \\
\text { et al. } \\
\text { (oral commu- } \\
\text { nication 2010) }\end{array}$ & $\begin{array}{c}\text { Motwani } \\
\text { et al. } \\
\text { (BMT 2005)8 }\end{array}$ \\
\hline Patient nr & 24 & 21 & 27 & 60 & 7 \\
\hline Conditioning & $\begin{array}{c}\text { TBI } 300 \mathrm{cGy} \\
\text { CY } 40 \mathrm{mg} / \mathrm{kg}, \\
\text { FLU } 140 \mathrm{mg} / \mathrm{m}^{2}, \\
\text { ATG, CsA }\end{array}$ & $\begin{array}{c}\text { TBI } 450 \mathrm{cGy}, \\
\text { CY } 40 \mathrm{mg} / \mathrm{kg}, \\
\text { FLU } 150 \mathrm{mg} / \mathrm{m}^{2}, \\
\text { ATG, TCD, } \\
\text { tacrolimus }\end{array}$ & $\begin{array}{c}\text { TBI } 300-450 \mathrm{cGy}, \\
\text { CY } 40 \mathrm{mg} / \mathrm{kg}, \\
\text { FLU } 150-180 \mathrm{mg} / \mathrm{m}^{2} \text {, } \\
\text { ATG, } \\
\text { tacrolimus }\end{array}$ & $\begin{array}{c}\text { CY } 60 \mathrm{mg} / \mathrm{kg} \\
\text { FLU } 125 \mathrm{mg} / \mathrm{m}^{2}, \\
\text { ATG, CsA }\end{array}$ & $\begin{array}{c}\text { CY } 20-30 \mathrm{mg} / \mathrm{kg}, \\
\text { FLU } 125 \mathrm{mg} / \mathrm{m}^{2}, \\
\text { ATG }\end{array}$ \\
\hline Ac GVHD & $23 \%$ & $5,5 \%$ & $11 \%$ & & $71 \%$ \\
\hline Cr GVHD & & $5,5 \%$ & $30 \%$ & & $28 \%$ \\
\hline $\begin{array}{l}\text { Follow-up } \\
\text { OS }\end{array}$ & $\begin{array}{r}\text { short } \\
86 \%\end{array}$ & $\begin{array}{r}5 \text { yrs } \\
72 \%\end{array}$ & $\begin{array}{c}3,1 \mathrm{yrs} \\
96 \%\end{array}$ & $\begin{array}{c}5 \text { yrs } \\
92 \% \text { pt }<10 \text { yrs age, } \\
53 \% \text { pt }>10 \text { yrs age }\end{array}$ & $\begin{array}{l}3 \text { yrs } \\
100 \%\end{array}$ \\
\hline
\end{tabular}

CsA: Cyclosporine A. 
advanced MDS or AML in FA patients. A report of 4 patients treated with a reduced intensity chemotherapy course (mini-FLAG) showed not more than expected haematological toxicity and no organ toxicity. Three of 4 patients had a marrow response and could be transplanted in aplasia, one patient required other chemotherapy to clear blasts pre-HSCT. ${ }^{16}$ The results do not answer whether chemotherapy given before HSCT may improve the poor survival. An alternative approach is to proceed to HSCT without prior cytoreduction, using TBI $300 \mathrm{cGy}$, cyclophosphamide $40 \mathrm{mg}$, Flu $140 \mathrm{mg}$, ATG, and TCD in conditioning regimen. ${ }^{17}$

Finally, taking care of a FA patient and his/her family is a great challenge due to the delicate balance between treating to cure on one hand and limiting the damage and side effects that the treatment causes to a crosslinker sensitive patient on the other hand.

\section{References}

1. Alter BP. Inherited Bone Marrow Failure Syndromes: Fanconi Anemia. In: D.G Nathan et al., editors. Nathan and Oski's Hematology of Infancy and Childhood. $6^{\text {th }}$ edition, Philadelphia: Saunders; 2003. p. 281-299.

2. Tipping AJ, Pearson T, Morgan NV, et al. Molecular and genealogical evidence for a founder effect in Fanconi anemia families of the Afrikaner population of South Africa. Proc Natl Acad Sci U S A 2001;98:5734-9.

3. Callen E, Casado JA, Tischkowitz MD, et al. A common founder mutation in FANCA underlies the world's highest prevalence of Fanconi anemia in Gypsy families from Spain. Blood 2005;105:1946-9.

4. Mehta PA, Harris RE, Davies SM, et al. Numerical chromosomal changes and risk of development of myelodysplastic syndromeacute myeloid leukemia in patients with Fanconi anemia. Cancer Genet Cytogenet 2010;203:180-6.

5. Pasquini R, Carreras J, Pasquini MC, et al. HLA-matched sibling hematopoietic stem cell transplantation for fanconi anemia: comparison of irradiation and nonirradiation containing conditioning regimens.
Biol Blood Marrow Transplant 2008; 14:1141-7.

6. Wagner JE, Eapen M, MacMillan ML, et al. Unrelated donor bone marrow transplantation for the treatment of Fanconi anemia. Blood 2007;109:2256-62.

7. MacMillan ML, Blazar BR, DeFor TE, et al. Alternate Donor HCT for Fanconi Anemia (FA): Results of a Total Body Irradiation (TBI) Dose De-Escalation Study. Biol Blood Marrow Transpl 2009;15:3-4.

8. Motwani J, Lawson SE, Darbyshire PJ. Successful HSCT using nonradiotherapybased conditioning regimens and alternative donors in patients with Fanconi anaemia-experience in a single UK centre. Bone Marrow Transplant 2005; 36:405-10.

9. Bonfim CM, de Medeiros CR, Bitencourt MA, et al. HLA-matched related donor hematopoietic cell transplantation in 43 patients with Fanconi anemia conditioned with $60 \mathrm{mg} / \mathrm{kg}$ of cyclophosphamide. Biol Blood Marrow Transplant 2007;13:1455-60.

10. Gluckman E, Rocha V, Ionescu I, et al. Eurocord-Netcord and EBMT. Results of unrelated cord blood transplant in fanconi anemia patients: risk factor analysis for engraftment and survival. Biol Blood Marrow Transplant 2007;13:1073-82.

11. Rosenberg PS, Socié G, Alter BP, Gluckman E. Risk of head and neck squamous cell cancer and death in patients with Fanconi anemia who did and did not receive transplants. Blood 2005;105:67-73.

12. Guardiola P, Pasquini R, Dokal I, et al. Outcome of 69 allogeneic stem cell transplantations for Fanconi anemia using HLAmatched unrelated donors: a study on behalf of the European Group for Blood and Marrow Transplantation. Blood 2000;95: 422-9.

13. de Medeiros CR, Bitencourt MA, ZanisNeto J, et al. Allogeneic hematopoietic stem cell transplantation from an alternative stem cell source in Fanconi anemia patients: analysis of 47 patients from a single institution. Braz J Med Biol Res 2006;39:1297-304.

14. Vadnerkar A, Nguyen MH, Mitsani D, et al. Voriconazole exposure and geographic location are independent risk factors for squamous cell carcinoma of the skin among lung transplant recipients. J Heart Lung Transplant 2010;29:1240-4.

15. Dufour C, Corcione A, Svahn J, et al. TNFalpha and IFN-gamma are overexpressed in the bone marrow of Fanconi anemia patients and TNF-alpha suppresses erythropoiesis in vitro. Blood 2003;102:2053-9.

16. Mehta PA, Ileri T, Harris RE, et al. Chemotherapy for myeloid malignancy in children with Fanconi anemia. Pediatr Blood Cancer 2007;48:668-72.

17. MacMillan ML, Wagner JE. Haematopoeitic cell transplantation for Fanconi anaemia - when and how? Br J Haematol 2010;149:14-21.

18. Dufour C, Rondelli R, Locatelli F, et al. Stem cell transplantation from HLAmatched related donor for Fanconi's anaemia: a retrospective review of the multicentric Italian experience on behalf of AIEOP-GITMO. Br J Haematol 2001;112: 796-805.

19. Farzin A, Davies SM, Smith FO, et al. Matched sibling donor haematopoietic stem cell transplantation in Fanconi anaemia: an update of the Cincinnati Children's experience. Br J Haematol 2007; 136:633-40.

20. Tan PL, Wagner JE, Auerbach AD, et al. Successful engraftment without radiation after fludarabine-based regimen in Fanconi anemia patients undergoing genotypically identical donor hematopoietic cell transplantation. Pediatr Blood Cancer 2006;46:630-6.

21. Ayas M, Al-Jefri A, Al-Seraihi A, et al. Matched-related allogeneic stem cell transplantation in Saudi patients with Fanconi anemia: 10 year's experience. Bone Marrow Transplant 2008;42:S45-8.

22. Chaudhury S, Auerbach AD, Kernan NA, Small TN, et al. Fludarabine-based cytoreductive regimen and T-cell-depleted grafts from alternative donors for the treatment of high-risk patients with Fanconi anaemia. Br J Haematol 2008;140:644-55.

23. Yabe H, Inoue H, Matsumoto M, et al. Allogeneic haematopoietic cell transplantation from alternative donors with a conditioning regimen of low-dose irradiation, fludarabine and cyclophosphamide in Fanconi anaemia. Br J Haematol 2006;134: 208-12. 